\title{
Association of Genetic Ancestry With DNA Methylation Changes in Prostate Cancer Disparity
}

\author{
VICTOR APPREY ${ }^{1}$, SONGPING WANG ${ }^{2}$, WEI TANG ${ }^{3}$, RICK A. KITTLES ${ }^{4}$, \\ WILLIAM M. SOUTHERLAND ${ }^{2}$, MICHAEL ITTMANN ${ }^{5}$ and BERNARD KWABI-ADDO ${ }^{2}$ \\ ${ }^{1}$ Department of Family Medicine, Howard University, Washington, DC, U.S.A.; \\ ${ }^{2}$ Department of Biochemistry and Molecular Biology Howard University, Washington, DC, U.S.A.; \\ ${ }^{3}$ Laboratory of Human Carcinogenesis, Division of Cancer Control and Population Sciences, \\ National Cancer Institute, National Institutes of Health, Bethesda, MD, U.S.A.; \\ ${ }^{4}$ Division of Health Equities, Department of Population Sciences, City of Hope, Duarte, CA, U.S.A.; \\ ${ }^{5}$ Department of Pathology and Immunology, Baylor College of Medicine, Houston, TX, U.S.A.
}

\begin{abstract}
Background: We hypothesized that ancestrymediated methylated DNA changes may drive racial and ethnic disparity in prostate cancer $(\mathrm{PCa})$. To test this hypothesis, we analyzed genetic ancestry and association with DNA methylation changes in PCa disparity. Materials and Methods: Pyrosequencing and ancestry informative markers were used for DNA methylation and genetic ancestry testing, respectively. Results: Using Spearman rho rank correlation test, the data demonstrated significant $(p<0.05)$ and variable association between African-American ancestry and DNA methylation for all genes investigated in prostate tissues. Conclusion: Genetic ancestry influences DNA methylation and this modifying factor must be considered in epigenetic association studies in populations of admixed patients.
\end{abstract}

Several epidemiological studies show that African-American (AA) men or men of African ancestry suffer disproportionate prostate cancer $(\mathrm{PCa})$ incidence and mortality rates compared to European-American (EA) men $(1,2)$. Data from autopsy studies have shown greater incidence of high-grade prostate intraepithelial neoplasia and $\mathrm{PCa}$ in AA men compared to age-matched EA counterparts $(3,4)$. In addition, several reports indicate that AA patients exhibited greater tumor volumes compared to similarly staged EA patients $(3,4)$. The disparity in $\mathrm{PCa}$ incidence and mortality rates is believed to

This article is freely accessible online.

Correspondence to: Bernard Kwabi-Addo, Ph.D., Department of Biochemistry and Molecular Biology, 520 W Street NW, Washington, DC 20059, U.S.A. Tel: +1 2028069149, Fax: +1 2026671686, e-mail: bkwabi-addo@howard.edu

Key Words: AIMs, DNA methylation, prostate cancer, disparity. be a complex combination of socioeconomic factors, lifestyle/environmental exposures and biology (5). The latter, including dietary choice, particularly the greater consumption of meat (6) and fat intake among AA men (7), may potentially contribute to increased risk of $\mathrm{PCa}$ and the more aggressive nature of the disease seen in AA men. However, after adjusting for socioeconomic factors and other exposures, the rate of $\mathrm{PCa}$ incidence in $\mathrm{AA}$ men is still disproportionate (5). Thus biological differences account for a significant part of the disparity in incidence and mortality for PCa in AA men in comparison to EA men (5).

Several studies have reported genetic differences, including mutation, loss, and amplification of chromosomal regions, contribute to the disparity of PCa risk between AA and EA men. Recent genomic advances have identified several markers that correlate with aggressive phenotypes in $\mathrm{PCa}$. The transmembrane serine protease 2- ETS transcription factor (TMPRSS2-ERG) fusion results in androgen-regulated overexpression of ERG, which is thought to play a critical role in PCa (8). The TMPRSS2-ERG fusion is found in more than $50 \%$ of EA men and in fewer than $30 \%$ of AA men with $\mathrm{PCa}(8,9)$, suggesting a high frequency of the ERG-negative phenotype in AA men. Comparison of primary tumors from AA men with those of EA men with similar pathological characteristics using high-throughput methods such as comparative genomic hybridization arrays and singlenucleotide polymorphism (SNP) analysis has identified a higher loss of frequency at numerous loci including 6q13-22, 8p21, 13q13-14 and 16q11-24 and gains of 7p21 and 8q24 (10). Genome-wide association studies utilizing large numbers of PCa cases and non-cancerous control samples, in conjunction with powerful statistical and other computational tools, has produced robust data for assessing genetic variants (SNPs) and association with traits or disease in different individuals or populations. For instance SNPs in genes for 
vitamin D metabolic and signaling pathway, kallikrein-related peptidase 3 locus and 5 - $\alpha$-reductase type 2 demonstrate differential frequencies in AA men than EA men and may play a role in PCa susceptibility or aggressiveness in these two groups (11-13). Allelic frequencies of several genes in androgen signaling pathways have been shown to differ in AA and EA populations (14). However, like susceptibility, these associations are not consistent.

In addition to genetic alterations, substantial evidence exists to support a role for epigenetic defects, such as DNA methylation changes and histone modifications (methylation/acetylation), in the development of PCa (15, 16). Epigenetic inactivation of genes in cancer cells is largely based on transcriptional silencing by aberrant $\mathrm{CpG}$ methylation of CpG-rich promoter regions $(17,18)$. The $\mathrm{CpG}$ dinucleotide marks are established and maintained by DNA methyltransferases (DNMTs) which catalyze the transfer of methyl group from S-adenosyl-methionine to cytosine bases in CpG dinucleotides, and three active enzymes (DNMT1, DNMT3a and DNMT3b) have been identified in mammalian cells (19). Several reports indicate the presence of functionaltering SNPs of DNMT3b, which can cause aberrant methylation and thereby contribute to tumorigenesis (20). To date, the most compelling findings are SNPs identified within chromosome 8q24 locus as genetic susceptibility factors for individuals of African ancestry with PCa (21). However, the risk variants are in non-protein coding regions and the biological mechanisms underlying this association remain unclear. Here we investigated the importance of genetic ancestry as a modifying factor in DNA methylation studies in admixed population of AA and EA men in contributing to prostate cancer disparity.

\section{Materials and Methods}

Patient samples. This study consisted of a total of 65 prostate tissue samples from men self-identified as AA consisting of 24 matched pairs of benign and $\mathrm{PCa}$ samples and 41 organ donor samples. The age range for patients with $\mathrm{PCa}$ was between 47 and 75 years old and for the controls (benign and organ donors) between 17 and 84 years old. This study was performed with Howard University Institutional Review Board approval (\#IRB-12-MED-75). Pathological characteristics of these cases are previously described $(22,23)$.

Global genetic ancestry. Global genetic ancestry analysis was performed as previously described (24). Briefly, prostate tissue DNA samples from a total of 65 patients mentioned above were genotyped for 100 ancestry informative markers (AIMs) using the Sequenom MassARRAY iPLEX platform (Sequenom, San Diego, CA, USA). The AIMs panel consisted of carefully selected autosomal markers previously identified and validated for estimating continental ancestry information in admixed populations $(25,26)$. Individual SNP genotype calls were generated using the Sequenom TYPER software. A genotype concordance rate of $99.5 \%$ was observed for all markers. Genotyping call rates exceeded $96 \%$ for all individuals included in the analyses. Individual admixture estimates for each study participant were calculated using a model-based clustering method as implemented in the program STRUCTURE v2.3 (27). As the ancestries of our samples were unclear, we used the admixture model to determine which estimation of $\mathrm{K}$ (number of sub populations) gave the best fit for the data. We set $\mathrm{K}$ from 2 to 5 and ran 100 iterations. We determined that $\mathrm{k}=3$ had the best fit and used the $\mathrm{K}=3$ estimates for our analyses.

Genotyping and DNA methylation analysis. High molecular weight genomic DNA was isolated from fresh-frozen prostate tissues using the DNeasy ${ }^{\circledR}$ isolation kit following the manufacturer's directions for purification from human tissues (Qiagen, Valencia, CA, USA). DNA concentration was measured using the Nanodrop Spectrophotometer (Nanodrop, Wilmington, DE, USA). Analysis of DNA methylation was carried out for four genes namely NK2 homeobox 5 (NKX2-5), glutathione S-transferase pi 1 (GSTP1), androgen receptor $(A R)$ and retinoic acid receptor beta $2(R A R B 2)$ by pyrosequencing as previously described (28).

Statistical analysis. Correlation analysis was performed using the $\mathrm{R}$ environment for statistical computing (version 3.5.2) with Spearman method and Spearman's rho for rank correlation. For each SNP genotype, tests using the genotypic dominant, recessive and logadditive genetic models were performed. Odds ratio (OR) and $95 \%$ confidence intervals (CIs) were calculated. Values of $p<0.05$ was considered statistically significant.

\section{Results}

A total of 65 patient samples were used in this study from those self-identified as AA men to estimate admixture of West African, Native American and European ancestry in this population. We assessed whether individual ancestry influenced DNA methylation by carrying out correlation analysis between individual ancestry and promoter methylation status of NKX2-5, GSTP1, AR and RARB2 genes (Figure 1). Analysis of African ancestry and DNA methylation using combined matched normal and prostate cancer samples demonstrated direct and significant correlation for $N K X 2-5(\mathrm{r}=0.43, p=0.001)$; and $R A R B 2$ $(\mathrm{r}=0.29, p=0.04)$. In contrast, correlation analysis of African ancestry and DNA methylation using organ donor samples demonstrated a significant inverse association between African ancestry and DNA methylation for only RARB2 gene $(\mathrm{r}=-0.34, p=0.046)$. When we determined whether European admixture percentages influenced the association, we observed that for the matched normal and prostate cancer tissues, EA ancestry was significantly and inversely associated with $N K X 2-5(\mathrm{r}=-0.43, p=0.001)$ and $R A R B 2$ $(\mathrm{r}=-0.28, p=0.04)$. However, for the organ donor samples, there was no significant association between the percentage of European ancestry and DNA methylation levels. When we tested whether the Native American admixture percentage influenced the association with methylation in matched normal and prostate cancer, we observed a significant and inverse association for AR $(r=-0.35, p=0.0344)$ only. 


\section{Matched normal and cancer samples}

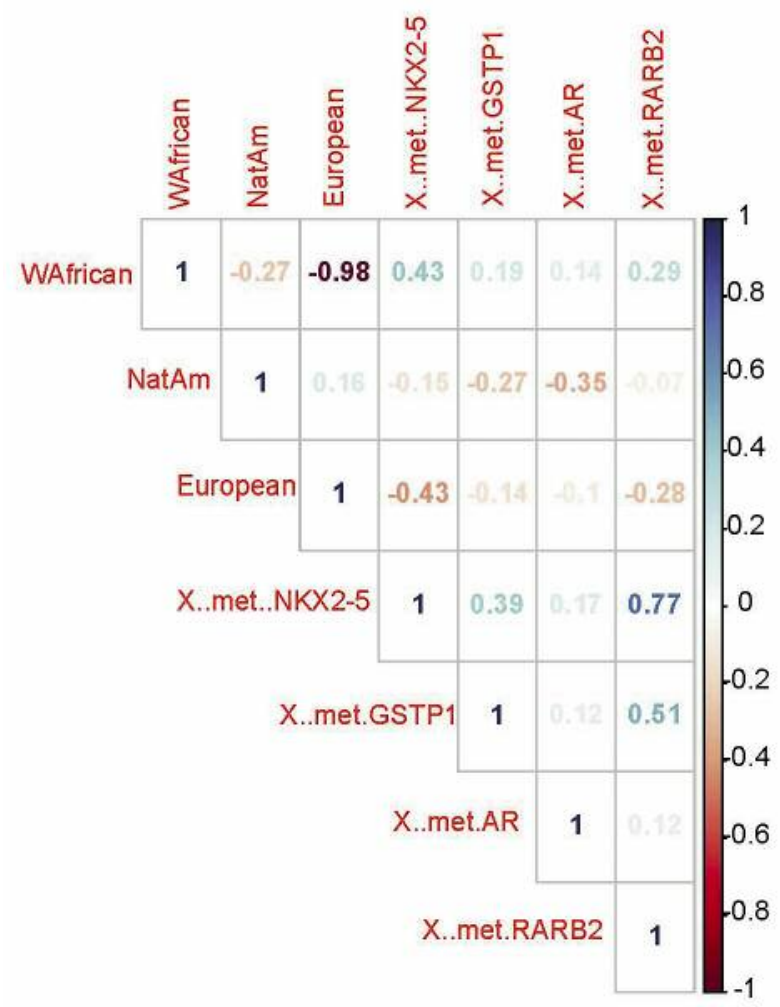

Organ donor samples

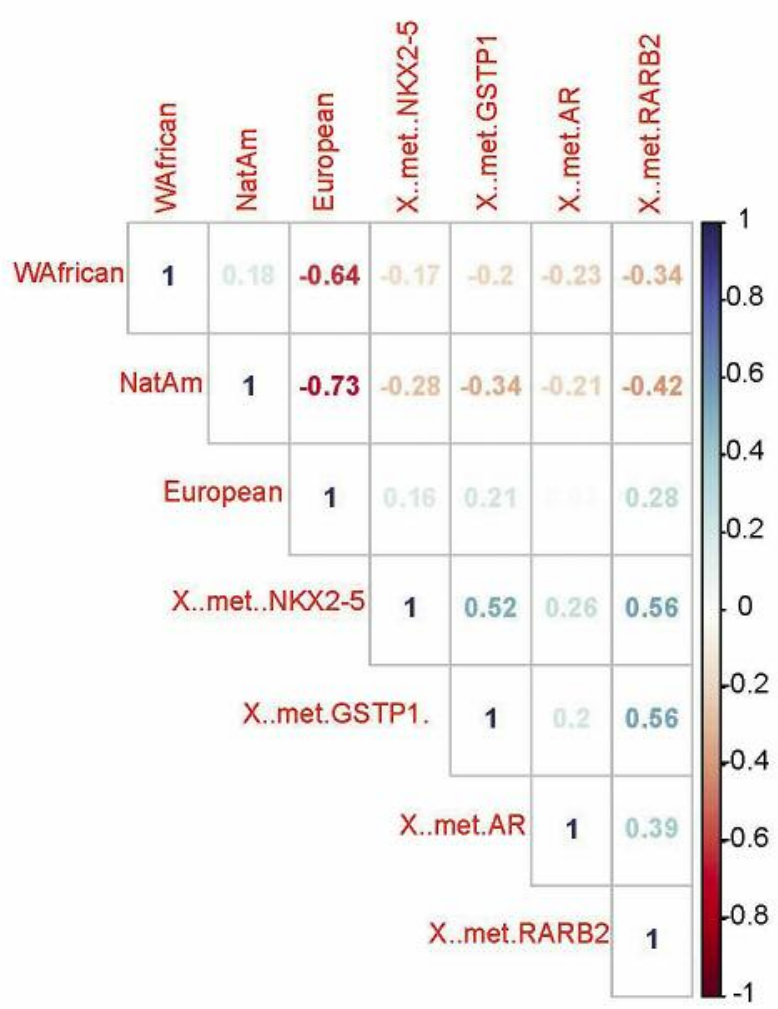

Figure 1. Correlation of genetic ancestry with DNA methylation changes in different racial/ethnic groups. The association of West African (WAfrican); Native American (NatAm) and European ancestry was correlated with DNA methylation changes in NK2 homeobox 5 (NKX2-5), glutathione $S$-transferase pi 1 (GSTP1), androgen receptor (AR) and retinoic acid receptor beta 2 (RARB2) promoter. Significant and direct correlation of DNA methylation and West African ancestry were observed for NKX2-5 gene $(p=0.001)$ and RARB2 $(p=0.04)$ in the matched normal and prostate cancer samples. European admixture was significantly and inversely associated with methylation of NKX2-5 gene ( $p=0.001)$ and RARB2 ( $p=0.04)$ and Native American admixture was significantly and inversely associated with methylation of AR gene $(p=0.034)$ in the matched normal and prostate cancer samples. Significant and inverse correlation of DNA methylation and West African ancestry was observed for RARB2 gene ( $p=0.046)$ using organ donor samples, and Native American admixture was significantly and inversely associated with methylation of RARB2 ( $p=0.012)$. Spearman rank correlation rho $(r)$ is reported.

Similarly, in organ donor samples, there was significant and inverse association for $R A R B 2$ ( $\mathrm{r}=-0.42, p=0.012$ ). Our findings of varying correlation pattern between DNA methylation and ancestry suggests that ancestry is associated with DNA methylation changes and this is supportive of previous observations of allele-specific methylation in prostate cancer (29).

\section{Discussion}

Genetic analysis of PCa indicates that there is no predominant genetic pathway associated with disease etiology, progression or disease disparity. Genetic variants such as SNPs are the most common genetic alterations with biological function that affect the genome and chromatin organization and ultimately gene expression at the cellular level and may contribute to $\mathrm{PCa}$ susceptibility and PCa disparity. For human PCa, abundant evidence has accumulated to suggest that somatic epigenetic alterations such as DNA methylation may appear earlier during cancer development than genetic changes, as well as more commonly and consistently (30). The aberrant promoter methylation of GSTP1, whose protein product functions in drug metabolism as a free radical scavenger, remains the most common somatic genome abnormality (>90\% of cases) reported thus far for PCa, appearing earlier and more frequently than other gene defects that arise during PCa development (31), and suggests that CpG hypermethylation may be particularly important in prostate carcinogenesis $(32,33)$. In addition to GSTP1 being frequently hypermethylated in $\mathrm{PCa}$, over 40 genes have been reported to 
be targets of DNA hypermethylation-associated epigenetic gene silencing in PCa cells (34). However, few studies that have reported ethnic/racial differences in DNA methylation. One study demonstrated that GSTPI hypermethylation was significantly higher in PCa samples from AA men in comparison with EA and Asians (35). Another study found higher frequency of hypermethylation of cell adhesion molecule (CD44) in PCa tissues from AA in comparison to EA men (36), suggesting that inactivation by $\mathrm{CpG}$ methylation may play a role in $\mathrm{PCa}$ disparity.

We previously demonstrated significant differences in DNA methylation at gene-specific promoters and genomewide scale and identified the differential methylation of several regulatory genes including GSTPI, AR, secreted protein acidic and cysteine rich $(S P A R C)$, metallopeptidase inhibitor 3 (TIMP3), macrophage-stimulating 1 receptor $(M S T 1 R)$, ATP-binding cassette subfamily $\mathrm{G}$ member 5 $(A B C G 5)$, small nuclear ribonucleoprotein $(S N R P N)$ and $N K X 2-5$ in matched samples of prostate tissues from AA and EA men $(28,37)$. The few studies on differential epigenetic changes in AA and EA men, as shown by us and others, show extensive variation in DNA methylation between individuals and ethnic groups. These differences arise from a combination of genetic and non-genetic influences and potential modifiers by early life, environmental and inflammatory processes which accumulate over years, with increased prevalence of DNA hypermethylation at several gene loci which may affect AA men differently than EA men.

Integrative analysis of methylation and SNPs has uncovered widespread allele-specific methylation (ASM) in PCa, with most DNA methylation changes occurring in the context of allele-specific methylation to suggest that variations in tumor epigenetic landscape of individuals are partly mediated by genetic differences which may affect the disease progression (29).

In the present study, we investigated AIMs and the causal relationship with DNA methylation and PCa disparity. We found a negative correlation between EA and methylationmediated PCa risk, whereas we found a positive correlation between AA and methylation-mediated PCa. Our findings suggest that the admixture process influences DNA methylation patterns and underscore the importance of association studies in admixed population such as USA AA men.

\section{Conclusion}

The current literature demonstrates the importance of understanding ancestry-related differences in PCa risk. Most genetic research work, to date, on $\mathrm{PCa}$ has been carried out using EA samples with very little data on AA men, an understudied population and one at a higher risk of $\mathrm{PCa}$ in comparison with any other racial or ethnic population. The biological consequences of differential DNA methylation changes are not well established in PCa disparity. The few epigenetic studies, as reported by us and others for DNA methylation in different ethnic/racial groups suggests that variants associated with differential methylation changes in AA and EA men may lead to differences in tumor biology and tumor aggressiveness between the two patient groups. Furthermore, the intriguing association between ancestry and epigenetic changes illustrates the potential for human genomics to stimulate more refined scientific questions for investigating population-specific interactions of lifestyle environmental, epigenomic and genetic factors in driving important phenotypes such as disease risk and xenobiotic response.

\section{Conflicts of Interest}

The Authors declare no conflicts of interest regarding this study.

\section{Authors' Contributions}

Victor Apprey and Wei Tang: Statistical analysis. Songping Wang: Methylation analysis by pyrosequencing. Rick Kittles: Genetic ancestry analysis. William Southerland: Provided Computational support. Michael Ittmann: Provided biospecimen for analysis. Bernard Kwabi-Addo: Provided conceptual idea and wrote the article.

\section{Acknowledgements}

This work was supported by a grant from Department of Defense Program Idea Award; PC073828 to Bernard Kwabi-Addo and grant 2U54MD007597 from NIMHD, NIH to the RCMI program at Howard University.

\section{References}

1 Hoffman RM, Gilliland FD, Eley JW, Harlan LC, Stephenson RA, Stanford JL, Albertson PC, Hamilton AS, Hunt WC and Potosky AL: Racial and ethnic differences in advanced-stage prostate cancer: the Prostate Cancer Outcomes Study. J Natl Cancer Inst 93: 388-395, 2001. PMID: 11238701. DOI: 10.1093/jnci/93.5.388

2 Platz EA, Rimm EB, Willett WC, Kantoff PW and Giovannucci E: Racial variation in prostate cancer incidence and in hormonal system markers among male health professionals. J Natl Cancer Inst 92: 2009-2017, 2000. PMID: 11121463. DOI: 10.1093/ jnci/92.24.2009

3 Moul JW, Connelly RR, Mooneyhan RM, Zhang W, Sesterhenn IA, Mostofi FK and McLeod DG: Racial differences in tumor volume and prostate specific antigen among radical prostatectomy patients. J Urol 162: 394-397, 1999. PMID: 10411045. DOI: 10.1016/j.urology.2014.08.043

4 Sanchez-Ortiz RF, Troncoso P, Babaian RJ, Lloreta J, Johnston DA and Pettaway CA: African-American men with nonpalpable prostate cancer exhibit greater tumor volume than matched white men. Cancer 107: 75-82, 2006. PMID: 16736511. DOI: 10.1002/cncr.21954 
5 Freedland SJ and Isaacs WB: Explaining racial differences in prostate cancer in the United States: sociology or biology? Prostate 62: 243-252, 2005. PMID: 15389726. DOI: 10.1002/ pros.20052

6 Rodriguez C, McCullough ML, Mondul AM, Jacobs EJ, Chao A, Patel AV, Thun MJ and Calle EE: Meat consumption among Black and White men and risk of prostate cancer in the Cancer Prevention Study II Nutrition Cohort. Cancer Epidemiol Biomarkers Prev 15: 211-216, 2006. PMID: 16492907. DOI: 10.1158/1055-9965

7 Gans KM, Burkholder GJ, Risica PM and Lasater TM: Baseline fat-related dietary behaviors of white, Hispanic, and black participants in a cholesterol screening and education project in New England. J Am Diet Assoc 103: 699-706, 2003. PMID: 12778040. DOI: $10.1053 /$ jada.2003.50135

8 Petrovics G, Liu A, Shaheduzzaman S, Furusato B, Sun C, Chen Y, Nau M, Ravindranath L, Chen Y, Dobi A, Srikantan V, Sesterhenn IA, McLeod DG, Vahey M, Moul JW and Srivastava S: Frequent overexpression of ETS-related gene-1 (ERG1) in prostate cancer transcriptome. Oncogene 24: 3847-3852, 2005. PMID: 15750627. DOI: 10.1038/sj.onc.1205818

9 Magi-Galluzzi C, Tsusuki T, Elson P, Simmerman K, LaFargue C, Esgueva R, Klein E, Rubin MA and Zhou M: TMPRSS2ERG gene fusion prevalence and class are significantly different in prostate cancer of Caucasian, African-American and Japanese patients. Prostate 71: 489-497, 2011. PMID: 20878952. DOI: $10.1002 /$ pros. 21265

10 Castro P, Creighton CJ, Ozen M, Berel D, Mims MP and Ittmann M: Genomic profiling of prostate cancers from African American men. Neoplasia 11: 305-312, 2009. PMID: 19242612. DOI: $10.1593 /$ neo. 81530

11 Zeigler-Johnson CM, Walker AH, Mancke B, Spangler E, Jalloh M, McBride S, Deitz A, Malkowicz SB, Ofori-Adjei D, Gueye SM and Rebbeck TR: Ethnic differences in the frequency of prostate cancer susceptibility alleles at SRD5A2 and CYP3A4 Hum Hered 54: 13-21, 2002. PMID: 12446983. DOI: 10.1159/ 000066695

12 Bensen JT, Xu Z, Smith GJ, Mohler JL, Fontham ET and Taylor JA: Genetic polymorphism and prostate cancer aggressiveness: a case-only study of 1,536 GWAS and candidate SNPs in African-Americans and European-Americans. Prostate 73: 1122, 2013. PMID: 22549899. DOI: 10.1002/pros.22532

13 Richards Z, Batai K, Farhat R, Shah E, Makowski A, Gann PH, Kittles R and Nonn L: Prostatic compensation of the vitamin D axis in African American men. JCI Insight 2: e91054, 2017 PMID: 28138564. DOI: 10.1172/jci.insight.91054

14 Platz EA and Giovannucci E: The epidemiology of sex steroid hormones and their signaling and metabolic pathways in the etiology of prostate cancer. J Steroid Biochem Mol Biol 92: 237 253, 2004. PMID: 15663987. DOI:10.1016/j.jsbmb.2004.10.002

15 Jeronimo C, Bastian PJ, Bjartell A, Carbone GM, Catto JW, Clark SJ, Henrique R, Nelson WG and Shariat SF: Epigenetics in prostate cancer: biologic and clinical relevance. Eur Urol 60: 753766, 2011. PMID: 2171919. DOI: 10.1016/j.euroro.2011.06.035

16 Nakayama M, Bennett CJ, Hicks JL, Epstein JI, Platz EA, Nelson WG and De Marzo AM: Hypermethylation of the human glutathione S-transferase-pi gene (GSTP1) CpG island is present in a subset of proliferative inflammatory atrophy lesions but not in normal or hyperplastic epithelium of the prostate: a detailed study using laser-capture microdissection. Am J Pathol 163: $923-$
933, 2003. PMID: 12937133. DOI: 10.1016/s0002-9440(10) 63452-9

17 Feinberg AP and Tycko B: The history of cancer epigenetics. Nat Rev Cancer 4: 143-153, 2004. PMID: 14732866. DOI: 10.1038/ nrc1279

18 Jones PA and Baylin SB: The fundamental role of epigenetic events in cancer. Nat Rev Genet 3: 415-428, 2002. PMID: 12042769. DOI: $10.1038 / \mathrm{nrg} 816$

19 Shen H, Wang L, Spitz MR, Hong WK, Mao L and Wei Q: A novel polymorphism in human cytosine DNA-methyltransferase$3 \mathrm{~B}$ promoter is associated with an increased risk of lung cancer. Cancer Res 62: 4992-4995, 2002. PMID: 12208751. DOI: $10.1186 / \mathrm{bcr} 807$

20 Duan F, Cui S, Song C, Dai L, Zhao X and Zhang X: Systematic evaluation of cancer risk associated with DNMT3B polymorphisms. J Cancer Res Clin Oncol 141: 1205-1220, 2015. PMID: 25864488. DOI: 10.1080/15592294.2015

$21 \mathrm{Xu}$ J, Kibel AS, Hu JJ, Turner AR, Pruett K, Zheng SL, Sun J, Isaacs SD, Wiley KE, Kim ST, Hsu FC, Wu W, Torti FM, Walsh $\mathrm{PC}$, Chang BL and Isaacs WB: Prostate cancer risk associated loci in African Americans. Cancer Epidemiol Biomarkers Prev 18: 2145-2149, 2009. PMID: 19549807. DOI: 10.1158/10559965.EPI-09-0091

22 Devaney JM, Wang S, Funda S, Long J, Taghipour DJ, Tbaishat $R$, Furbert-Harris $P$, Ittmann $M$ and Kwabi-Addo $B$ : Identification of novel DNA-methylated genes that correlate with human prostate cancer and high-grade prostatic intraepithelial neoplasia. Prostate Cancer Prostatic Dis 16: 292300, 2013. PMID: 23896626. DOI: 10.1038/pcan.2013.21

23 Kwabi-Addo B, Chung W, Shen L, Ittmann M, Wheeler T, Jelinek J and Issa JP: Age-related DNA methylation changes in normal human prostate tissues. Clin Cancer Res 13: 3796-3802, 2007. PMID: 17606710. DOI: 10.1158/1078-0432.CCR-07-0085

24 Al-Alem U, Rauscher G, Shah E, Batai K, Mahmoud A, Beisner E, Silva A, Peterson C and Kittles R: Association of genetic ancestry with breast cancer in ethnically diverse women from Chicago. PLoS One 9: e112916, 2014. PMID: 25423363. DOI: 10.1371/journal.pone.0112916

25 Kosoy R, Nassir R, Tian C, White PA, Butler LM, Silva G, Kittles R, Alarcon-Riquelme ME, Gregersen PK, Belmont JW, De La Vega FM and Seldin MF: Ancestry informative marker sets for determining continental origin and admixture proportions in common populations in America. Hum Mutat 30: 69-78, 2009. PMID: 18683858. DOI: 10.1002/humu.20822

26 Nassir R, Kosoy R, Tian C, White PA, Butler LM, Silva G, Kittles R, Alarcon-Riquelme ME, Gregersen PK, Belmont JW, De La Vega FM and Seldin MF: An ancestry informative marker set for determining continental origin: validation and extension using human genome diversity panels. BMC Genet 10: 39, 2009. PMID: 19630973. DOI: 10.1186/1471-2156-10-39

27 Falush D, Stephens M and Pritchard JK: Inference of population structure using multilocus genotype data: linked loci and correlated allele frequencies. Genetics 164: 1567-1587, 2003. PMID: 12930761. DOI: 10.1534/genetics.109.109991

28 Kwabi-Addo B, Wang S, Chung W, Jelinek J, Patierno SR, Wang $\mathrm{BD}$, Andrawis R, Lee NH, Apprey V, Issa JP and Ittmann M: Identification of differentially methylated genes in normal prostate tissues from African American and Caucasian men. Clin Cancer Res 16: 3539-3547, 2010. PMID: 20606036. DOI: 10.1158/1078-0432.CCR-09-3342 
29 Lin PC, Giannopoulou EG, Park K, Mosquera JM, Sboner A, Tewari AK, Garraway LA, Beltran H, Rubin MA and Elemento $\mathrm{O}$ : Epigenomic alterations in localized and advanced prostate cancer. Neoplasia 15: 373-383, 2013. PMID: 23555183. DOI: 10.1593/neo.122146

30 Nelson WG, Yegnasubramanian S, Agoston AT, Bastian PJ, Lee BH, Nakayama $\mathrm{M}$ and De Marzo AM: Abnormal DNA methylation, epigenetics, and prostate cancer. Front Biosci 12: 4254-4266, 2007. PMID: 17485372. DOI: $10.2741 / 2385$

31 Nelson WG, De Marzo AM and Isaacs WB: Prostate cancer. N Engl J Med 349: 366-381, 2003. PMID: 12878745. DOI: 10.1056/NEJMra021562

32 Zingg JM and Jones PA: Genetic and epigenetic aspects of DNA methylation on genome expression, evolution, mutation and carcinogenesis. Carcinogenesis 18: 869-882, 1997. PMID: 9163670. DOI: $10.10931 \mathrm{carcin} / 18.5 .869$

33 Gonzalgo ML, Liang G, Spruck CH, III, Zingg JM, Rideout WM, III and Jones PA: Identification and characterization of differentially methylated regions of genomic DNA by methylation-sensitive arbitrarily primed PCR. Cancer Res 57: 594-599, 1997. PMID: 9044832. DOI: 10.1111/ecc.12336

34 Bastian PJ, Yegnasubramanian S, Palapattu GS, Rogers CG, Lin $\mathrm{X}$, De Marzo AM and Nelson WG: Molecular biomarker in prostate cancer: the role of $\mathrm{CpG}$ island hypermethylation. Eur Urol 46: 698-708, 2004. PMID: 18076941. DOI: 10.1016/j.juro. 2007.09 .038
35 Enokida H, Shiina H, Urakami S, Igawa M, Ogishima T, Pookot D, Li LC, Tabatabai ZL, Kawahara M, Nakagawa M, Kane CJ, Carroll PR and Dahiya R: Ethnic group-related differences in CpG hypermethylation of the GSTP1 gene promoter among African-American, Caucasian and Asian patients with prostate cancer. Int J Cancer 116: 174-181, 2005. PMID: 15800905. DOI: $10.1002 /$ ijc. 21017

36 Woodson K, Hayes R, Wideroff L, Villaruz L and Tangrea J: Hypermethylation of GSTP1, CD44, and E-cadherin genes in prostate cancer among US Blacks and Whites. Prostate 55: 199205, 2003. PMID: 12692786. DOI: 10.1002/pros.10236

37 Devaney JM, Wang S, Furbert-Harris P, Apprey V, Ittmann M, Wang BD, Olender J, Lee NH and Kwabi-Addo B: Genomewide differentially methylated genes in prostate cancer tissues from African-American and Caucasian men. Epigenetics 10: 319-328, 2015. PMID: 25864488. DOI: 10.1080/15592294.2015

Received September 16, 2019

Revised September 25, 2019 Accepted October 2, 2019 